\title{
INTERCULTURAL JOINT AWARENESS RAISING - "INJAWARA" - PROJECT FOR INTERCULTURAL COMPETENCE AND COOPERATION
}

\author{
Ch. Zafirov* \\ Faculty of Education, Trakia University - Stara Zagora, Bulgaria
}

\begin{abstract}
Subject of the report is the concept of the project-based learning in an academic environment, represented by the realization of a successful international project - "InJawara" in the Faculty of Education. The project was implemented in parallel in six European countries - Italy, Spain, Cyprus, Lithuania, France and Bulgaria. The main objective of the project was to encourage the participation of young people in the processes of global development of the world and support the understanding between all parties, with emphasis on sustainable development and social justice. Promoting the objectives of the Millennium Development Goals are achieved through a variety of activities: interactive learning, collaborative game, conferences, seminars, workshops, Internet contacts / Skype, social networks / festivals, joint events with nongovernmental organizations, the exchange of experiences with students from other partner countries.

Multifunctional nature of the project reflects positively on the participants, its effectiveness was determined by a complex of methods: observation, diagnostic interview, and test - game. The results obtained are classified by three criteria: cognition, affectivity, social and behavioural intelligence. The highest ratio of utility was achieved in the direction of the third criterion, expressed in: first, the development of a number of social skills (communication and cooperation, teamwork, persuasion and protection of ideas, reflection), second, changing attitude on global social issues of today, third, readiness for active position in solving them.
\end{abstract}

Key words: Project based learning, collaboration, interactive learning, millennium development goals, collaborative game.

\section{INTRODUCTION}

The "Intercultural Joint Awareness Raising In.J.Awa.Ra" is a European project which promotes the intercultural dialogue among the Global Youth. In.J.Awa.Ra encourages the participation of youth in global development issues and supports the development of a critical understanding of the relations between the Global North and South, with particular emphasis on sustainable development and social justice. In.J.Awa.Ra "sees" in dialogue the assertion of multiple and plural identities and in democratic and active participation the realization of the concept of global citizenship. The project is developed within the EuropeAid programme - Non-State actors and Local Authorities in Development (Raising public

"Correspondence to: Assist. Prof. Dipl. Eng. Christomir Zafirov, Faculty of Education, Trakia University - Stara Zagora, Bulgaria, christo@pf.uni-sz.bg awareness of development issues and promoting development education in the European Union and acceding countries) (1). It is a project created by the interaction and collaboration of six European cities and organizations in partnership with the European Union: Tamat NGO, Perugia (Italy): the project coordinator, Amsed, Asociación Migrations Solidarités \& Echanges pour le Developpment, Strasbourg (France), Cardet, Centre for the advancement of research \& development in educational technology, Nicosia (Cyprus), EuroTraining NGO, Stara Zagora (Bulgaria), Jarit, Asociación Civil in Valencia (Spain), Saretas, International Cooperation and Research Institute, Kaunas (Lithuania).

The general objective of the project was to make a contribution to the enhancement of the levels of information and proactive awareness of European citizens on the foundations, the 
dynamics as well as the effects of the relations between the Global North and South. Additionally, the specific objective of 'In.J.Awa.Ra' was to reinforce a widespread and collective conscience on Millennium Development Goals (MDGs) (2) www.un.org/millenniumgoals/ - able to cultivate public support for the development of the Least Developed Countries (LDCs) - based on EU policies and principles of solidarity, human rights and democracy. The objectives of the project were met through the promotion of development education and awareness raising efforts among the young citizens in 6 EU countries.

\section{NEEDS FROM THE PROJECT}

All the partners involved in In.J.Awa.Ra project identified development education gaps in their different regions countries: the rarity (if not the absence) of cross-initiatives in the field of intercultural and development education outside the formal education system, too few opportunities for stimulating intercultural dialogue among young generations offered by local entities, the limited innovation in development education field, too few opportunities for understanding and exchanges with LDCs citizens, few networking among youth associations and NGOs working with development cooperation. Despite all the cooperation national institutions (Ministries/national agencies) set the development education as one of the main priorities within the cooperation local policy, it remains marginal and often not provided in non-formal education settings in general.

A culture of human rights can only be achieved by educating people of all ages, in positions of influence and positions of vulnerability, about what development cooperation issues are and what is required for building a conscious citizenship.

People in general don't have a full awareness of international development priorities and sustainable human development, because don't know and understand exactly the causes and effects of globalization issues. At the same time they need to become aware of the extent to which problems affecting LDC in a globalized age like that one we are living in may have a negative impact on our lives as well. This lack of understanding on the difficulties facing developing countries and their peoples, and on the social and politic dynamics which affects relationship among North and South Countries is clearly observable among youth generations.
In Europe, development education in a broad sense is still lacking among youth and civil society and need to be further strengthened. This lack of awareness is reflected in the Eurobarometer where in its survey "Europeans and Development Aid" of 2007 (3), the 83\% (of which the $80 \%$ are young between 15 and 24 years old) of people from the six countries involved (the data represents an average between Bulgaria, Cyprus, France, Italy, Lithuania, Spain) replied "No" in the question "Have you ever heard or read about the Millennium Development Goals?". People don't have a full awareness of international development priorities and sustainable human development because don't know and understand exactly the causes and effects of globalization issues. At the same time they need to become aware of the extent to which problems affecting LDC in a globalized age like that one we're living in, may have a negative impact on our lives as well. The lack of awareness and intercultural dialogue among youth represent an extremely urgent problem in Europe: the increased economic inequality between North and South, the worsening environmental situation in many LDCs (as the desertification in Sub-Saharian Africa) shows that migrations trends towards Europe will continue to grow and that international cooperation has never been so important: it is necessary to conceive local initiatives in order to sensitize about this issues and stimulate living together in a pluralistic and respectful society. In particular, youth outside the formal education system are those who risk a greater isolation because they have few possibilities to be involved in intercultural and exchange.

\section{PROJECT ACTIVITIES}

The whole project was scheduled according on a specific work-plan of 24 months.

There are three specific activities responding to 3 main concepts:

Activity 1: Knowledge and Empowerment

Activity 2: Sharing and Play

Activity 3: Communication and Action

The activities have been developed according with specific attended results:

Result 1: Involvement of European youth and of youth associations of $6 \mathrm{EU}$ regions in development education, awareness raising process increased.

- Development of common curricula to be exploited in partners' countries on the themes of development cooperation and MDGs. Common basic curricula and tools were developed jointly by the partnership to be used in the activity (Implementation of meetings among partners and local youth associations) and (Implementation of 
educational workshop for youth). The curricula included a list of topics, basic competences and new skills that will have to be acquired by youth after the completion of the project. Topics referred to MDGs, EU approach to development cooperation (E.C. COM(2011) 637), ethic basis of development approaches, trustable sources of information.

- Implementation of meetings among partners and local youth associations. The partners organized cycles of meetings with local youth associations to share with them the objectives of In.J.Awa.Ra and the action plan of the project. Youth representatives were stimulated in activating a brainstorming process thanks to which, with the support of project's experts, they identified specific needs and problems of local youth inside their area of intervention: thus differences in terms of local context and the character of the youth association involved was strongly taken into account to build a training offer that responds to concrete needs and is adapted to local situation.

- Implementation of educational workshop for youth. Project's experts and youth representatives organized and managed educational workshops for about 1500 youngsters (their associates, other young people and young operators, etc.) using different tools and instruments. Workshops took the form of "Learning Circles" in which youth representatives themselves were the facilitators, supported by project's experts. The approach was based on active and non-discriminating methodology to involve youth as much as possible, including intercultural working and learning by doing methods.

Result 2: Intercultural exchanges among youth from 6 EU regions and LDCs on the themes of development cooperation fostered.

- Twinning between youth (target group) of the 6 partners' countries were achieved through the common use of blogs and social networks to exchange opinions, materials, photos, videos, etc. and the activity was further strengthened during the implementation of the other activities and the implementation of the National Competitions and the Development Festival.

- Twinning between EU youth of 6 EU Districts and LDC citizens were achieved through on-line debates, web-conferences, blogs and social networks. This is the same activity developed above, but including youth from developing countries, in which each partners is involved. So, it was not just getting in contact with unknown youngster from LDC, but discussing and getting in touch with people involved in developing projects with partners and/or partners' networks.

- Creation and implementation of the In.J.Awa.Ra "Development Board Game" and related In.J.Awa.Ra development national competitions. The In.J.Awa.Ra game proposes a model and "another thought" through its nature, as it can be appreciated as a cooperative game in which nobody wins, nobody loses and nobody is excluded. In.J.Awa.Ra game involves team-play, and not individuals pitted one against the other, as is the case in usual game models. Here players challenge themselves and the limits of their abilities by playing as a team to achieve a common goal. They have to come together to solve challenges grounded in real objectives: the 8 Millennium Development Goals set by the United Nations. The possibility to "win" is linked to the competence that the group and not the individual - has to answer questions related to these objectives, as well as the ability to collaborate and create common strategies through the use of resources based on real ones - economics, materials, education, policies, professionals, justice. The playful element is given by the totally imaginary feeling the team of players shares in having the possibility to use these resources to contribute to the struggle involved in global challenges and therefore the development of a better world. In this sense, the game holds its essence of relational knowledge and fun. Competition is not excluded, but it does not occur between individual players, but between the group and the game itself, guiding the players to have a goal, a project, and a common strategy. The knowledge of other models breaks the cultural absolutism favouring self-criticism and cultural relativism. To recognize an alternative, in this case, to the usual way to play (and live), means to understand the possibility that a different identity exists; to take into account other points of view within a pluralistic society, and teach, albeit through a different pattern of play "the danger of a single story" as put by the Nigerian writer Chimamanda Ngozi Adichie.

Implementation of the Development European Competitions: the final 6 winner teams, one from each partner country, were chosen to take part in the online 
In.J.Awa.Ra Development Board Game EU Competitions (among partner's countries). Furthermore, they were awarded with the participation (travels and accommodation were paid by the project) at the In.J.Awa.Ra Development Festival that was held in each partners' country. The project indicated that Italian winners will go to Lithuania, Spanish ones to Bulgaria, Lithuanians to France, Cypriots to Spain, Bulgarians to Italy and French to Cyprus. The decision was made to foster reciprocal knowledge and develop the European dimension.

Result 3: Young people and European citizens of the $6 \mathrm{EU}$ regions informed and involved in development issues and activities.

- Implementation of In.J.Awa.Ra communication outputs: gadgets, videos, CDs and other multimedia material were produced with the support, ideas, slogans, suggestions of youth themselves, with the tutorship of the project experts. The preparation of the communications outputs was precisely defined in the Dissemination and exploitation plan to give appropriate visibility to the project and to EU funding. The gadgets, thus, became a symbol of a community that cares for development issues, supporting the ownership of the project from the target group and were distributed during the Competitions, the Festivals and during events concerning youngsters.

- Implementation of a Learning Service in every partner's country. This activity was two folded. On one side, make the target groups main actors of the activity, giving them the responsibility of the choice and of the implementation of the Learning Service, that is conceived to promote awareness and knowledge on development issues among other citizens not involved in the project leaving the choice of the typology of the Service to the target group; on the other side, it gives visibility to the project and reaches final beneficiaries.

- Organization of the In.J.Awa.Ra Development Festivals. The festival was the final event of the project, and it was held in each partners' country, with the participation of youth and associations, winners of the Board Game, from the other partner's countries and with the active involvement of general public and student of primary and high schools, and university students as well involved in these events, through conferences, dinners and social events.

\section{THE METHODOLOGY}

Regarding the activities, the methodology adopted has been chosen with special regard to increase the participation of beneficiaries, favour the ownership and ensure sustainability. The identify methodology promotes an interactive - constructivist approach, by creating an environment for creative learning based on collaborative learning (problem solving and guided conversation) where the methods applied are those of learning by doing.

For these reasons the project team decided to work with youth association, and not just with youngsters, to support them to gain competences necessary to became protagonists and multiply the results, making them sustainable through next years.

To favour the participation of association and of youngster we furthermore decided to adopt active methodologies where the partners' role should be of support, mainly a "tool" to help youth association and youngster to achieve the results and to produce the main outputs.

In the activities the partnership used the "Learning Circle" approach, with the local youth associations acting as facilitators. Thus the youngsters were not only passive listeners, but they had to be active, "using" the project expert as a resource to answer to their needs. Furthermore, during this activity, facilitators and youngster with the support of project expert developed the questions/ answers that were used in the Board Game, favouring the ownership of this important output.

In the result "Sharing and Play" partners chose to use tools that are commonly and daily used by youngster, blogs, social networks, Facebook (5), You Tube, etc. By experience this was the best method to involve them.

Furthermore, we choose to develop with the beneficiaries the communication outputs, thus realizing outputs really tailor-made for the youngsters.

Finally, the involvement of LDCs youngsters by social networking and the LDCs privilege actors let the target group to better understand the contents on which we worked and let them compare their ideas on development with the real protagonist.

In result "Communication and Action" partners developed outputs to inform and raise awareness among youngster and citizen designed with the target group. Furthermore, implementation of a learning service in every 
partners' country, to let young people act as main actors of awareness rising on development issues.

\section{CONCLUSION}

Multifunctional nature of the project reflects positively on the participants, its effectiveness was determined by a complex of methods: observation, diagnostic interview, and test game. The results obtained are classified by three criteria: cognition, affectivity, social and behavioural intelligence. The highest ratio of utility was achieved in the direction of the third criterion, expressed in: first, the development of a number of social skills (communication and cooperation, teamwork, persuasion and protection of ideas, reflection), second, changing attitude on global social issues of today, third, readiness for active position in solving them.

\section{ACKNOWLEDGMENTS}

This project consumed huge amount of work, research and dedication. Still, implementation would not have been possible if we did not have a support of many individuals and organizations. Therefore we would like to extend our sincere gratitude to all of them.

First of all we are thankful to TAMAT, NGO project coordinator for their support and for providing necessary guidance concerning projects implementation.

We are also grateful to all project partners from for provision of expertise and support in the implementation. Without their superior knowledge and experience, the project would like in quality of outcomes, and thus their support has been essential.

We would like to express our sincere thanks towards all beneficiaries from different target groups who devoted their time, enthusiasm and knowledge in the implementation of this project.

\section{Project n. DCI-NSAED/2011/180}

This project has been funded with the support of the European Union. This communication reflects the views only of the author, and the Commission cannot be held responsible for any use which may be made of the information contained therein.

\section{REFERENCES}

1. https://ec.europa.eu/europeaid/home_en

2. http://www.un.org/millenniumgoals/

3. http://ec.europa.eu/public_opinion/archives/ ebs/eb

4. http://www.injawara.eu

5. http://www.facebook.com/injawara 